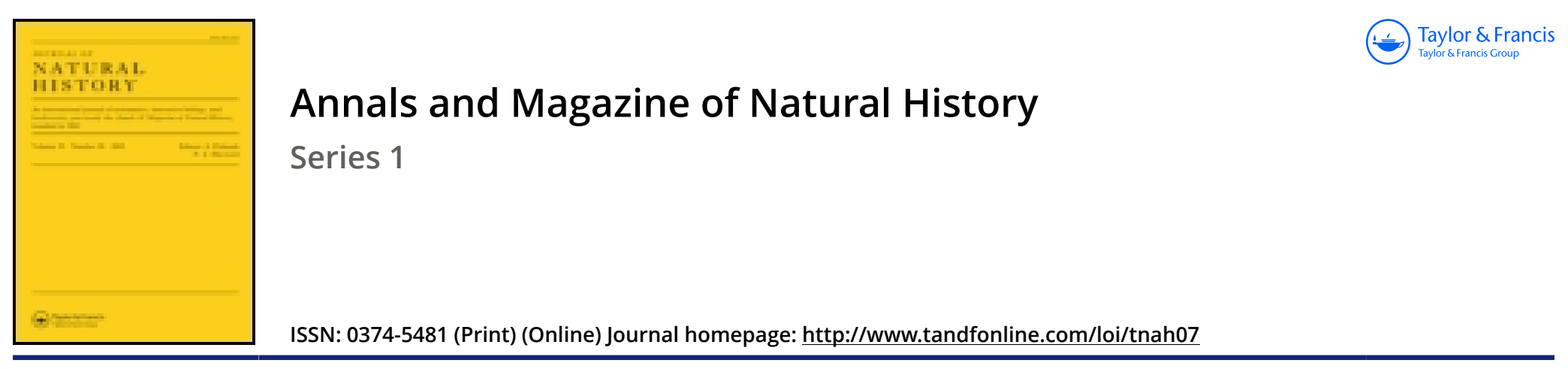

\title{
XLVI._On the organization of the Polygastric Infusoria
}

\section{Eckhard}

To cite this article: C. Eckhard (1847) XLVI._On the organization of the Polygastric Infusoria, Annals and Magazine of Natural History, 18:122, 433-452, DOI: 10.1080/037454809494456

To link to this article: http://dx.doi.org/10.1080/037454809494456

曲 Published online: 14 Dec 2009.

Submit your article to this journal ๘

Q View related articles $₫$ 
THE ANNALS

AND

\title{
MAGAZINE OF NATURAL HISTORY.
}

\author{
SUPPLEMENT TO VOL. XVIII. JANUARY 1847.
}

\section{XLVI.-On the Organization of the Polygastric Infusoria. By C. Eckнard*. \\ [With two Plates.]}

1. Since the discovery and the progressive perfection of the microscope, a new impulse has been given to all those branches of scientific study in which its use is applicable, from which we cannot withhold our acknowledgement, because it has enriched us with a number of the most interesting facts, which formerly could not have been anticipated. In botany, R. Brown, H. Mohl, M. J. Schleiden and others have investigated with success; and in the zoological and anatomical department the not less important researches of J. Müller, Bischoff, Schwann, Reichert, \&c. have appeared. Ehrenberg undoubtedly gave a most important impulse to all these microscopic inquiries by his numerous investigations in one class of animals, which before him had been examined by few only, and the anatomical and physiological relations of which at that time were almost unknown. Unfortunately however, this store of excellent observations has not been estimated according to its true value; to many it has been inaccessible, whilst others have either not repeated the observations, or only imperfectly, and have hence expressed views which have not stood the test of a critical examination. In the 'Lehrbuch der' vergleichenden Anatomie,' by Von Siebold and Stannius, which appeared last year, in the section on the Infusoria, Siebold has adopted views of their structure which totally differ from those of Ehrenberg. Consequently these required thorough elucidation, to separate mere opinions from what may be considered as welldetermined scientific facts ; especially since doubt has been thrown upon even Ehrenberg's views, although founded upon distinct observation. Schmidt has fully discussed Siebold's views on the structure of the Rotatoria in a previous part of this journal: I shall attempt to do so as regards the Polygastrica in this paper. My reasons for fully entering into the organization and physiology of these animals, are, on the one hand, that we are at present in possession of no treatise which lays before us the details' of this subject in connexion (for Ehrenberg's observations are widely

- 'Translated by Dr. J. W. Griffith from Wiegmann's Archiv, Part 3, 1846. Ann. \& Mag. N.Hist. Vol. xviii. Suppl. $2 \mathrm{I}$ 
scattered, and are only to be found in the large works on Infusoria), and, on the other hand, that I have made some new observations, which may probably possess interest.

2. Before passing on to the true demonstration of the relations of their organization, I must examine more minutcly an expression of Siebold in the work above quoted. It is as follows (p. 7): "But those infusoria which remain as Polygastrica (after the separation of the Rotatoria) require a further limitation, because those organisms which are enumerated among the Closterina, Bacillarina, Volvocina, and probably many other of Ehrenberg's animals, having stomachs but not intestines, must be referred to the vegetable kingdom." The dispute regarding the nature of these bodies is old, and dates from the time of their discovery. It has been renewed innumerable times, by both zoologists and botanists; nevertheless the truth is apparently not yet determined. Both manuals of botany and zoology frequently contain one and the same genus, or in fact, family. I fear that again to bring forward the question will be irksome to those who have long since satisfactorily proved the animal nature of the supposed plants, but I cannot refrain from so doing. It therefore first becomes requisite to attempt to restore to their proper place the three families referred by Siebold to the vegetable kingdom.

I. Closterina.--The grounds for their being of animal nature are derived partly from their motion, partly from their organization. On the leaves of Ceratophyllum, I observed the manner in which several Closteria adhered elegantly by one extremity ; in about a quarter or half an hour many of them were situated in the same manner upon a higher part of the leaf : not a single animalcule was found on the side of the leaf, nor adherent longitudinally to it. 'They had evidently moved during the above time from the lower to the upper part of the leaf. If we observe their motions under the microscope, they are not so rapid as those of many other polygastric infusoria, but the motion is always evidently animal. They swim, especially in summer, in the most varied directions, and I have frequently seen $C l$. acerosum and Lunula swim against the current when the water on the object-holder was flowing towards one side, whilst fragments of plants, various kinds of Spirogyra and Oscillatoria, were carried away. It is difficult here to discover anything but animal motion; to explain this however by electricity, as Turpin attempted*, is unnatural, and not less absurd than that of the muscular fibre by the same natural agent by Strauss. But the relations of the organization of the Closterina are likewise in favour of their animal nature. In illustration of this I shall confine myself to

* Sur les Closteries. 
Cl. acerosum, which is figured in Plate IX. B. fig. 1. We see that the animal, which is expanded in the middle, is elongated symmetrically on each side. In the middle there is a transverse fissure $m$, which probably serves for the admission of nourishment; since, when this animal is kept for some time in coloured water, we perceive little accumulations of the colouring matters. At the extremities we see on each side a vesicle $b$, in which minute granules (?) incessantly move. In other species there is moreover a small aperture $r$; it is situated more posteriorly, and is perhaps connected with the cell. Ehrenberg twice saw in this animalcule filaments (feet?) project from it. Internally there are, on each side, two to four cords, $s^{\prime} s^{\prime \prime} s^{\prime \prime \prime}$, and a row (in other kinds several) of glandular bodies $d$. In the species figured, I have so often seen the above change in relative position, that $I$ have been compelled to wait until they again appeared in their original position in order to delineate them. All this is not plant-like; and if the carapace of the Closterina should prove to be of a horny nature, as would appear to be the case from their becoming wrinkled when heated, they would be removed from the vegetable kingdom with still greater certainty.

II. Bacillarina.- The greatest doubt has certainly been raised regarding the animal nature of the forms which belong to this family. I think however that if we collect all the observations which have hitherto been made upon these bodies, they must bc referred to the animal kingdom. We will therefore consider the following :-

I have, a hundred times, seen Navicula Acus and Librile swim against the current as distinctly as the Closteria, so that these motions cannot be regarded otherwise than as dependent upon the will of the animals. In addition to this, the shells of all the Bacillarina are formed in a much more complicated manner (3) than the other inorganic parts which we commonly find in plants. We find calcareous incrustations,crystals, \&c., but never such symmetrically formed shells as in the Bacillarina. Plants have no such power over inorganic chemical agency as to elaborate inorganic matters according to their will independently of the laws of such matters, and such as we must presuppose to exist in the formation of the carapace of the Bacillarina. The exsertion of feet at the anterior, and probably also at the inferior apertures of the carapace, speaks decidedly in favour of the animal nature of the Navicula. Ehrenberg first detected it, and described it in the 'Transactions of the Berlin Academy *' After him it was observed by Schmidt, and in the latter part of the autumn of last year I succeeded in seeing it. Its not being more frequently detected, depends upon

* For the year 1836 , p. 134, and 1839, p. 102; and 'Taylor's Scientific Memoirs, Parts X. and XI. 
the fact that such phænomena cannot be produced, but depend upon fortunate circumstances, which we must take the chance of meeting with. Lastly, should the observation of Werneck*, who saw a Peridinium inside a Navicula and thought that it had been eaten by it, be true, as can scarcely be doubted from so acute an observer, the dispute regarding the nature of the Bacillarina would be at an end.

III. Volvocina.-How Siebold has been able to refer these to the regetable kingdom is to me incomprehensible; the distinct ascent and descent of Volvox globator, when kept in glasses, the spontaneous motion of the two proboscides of each separate animalcule, and the contractile vesicle discovered by Ehrenberg, leave no further doubt on this matter.

It still remains for us to bring forward and examine the grounds upon which Siebold based his opinion on the nature of the three families we have mentioned. At pages 8 and 9 we find the following remarks, which, if they cannot together be adduced as a direct ground for the author's view, nevertheless may serve as matter for further consideration :-

1) "It is quite different with the locomotions of the lowest vegetable organisms (among which, as we know, the farnilies above-mentioned are enumerated), since these are not the consequence of an internal voluntary influence, and do not arise from any spontaneously contractile and expansible parenchyma," \&c. It appears to me to follow with certainty from the observations detailed in $\mathbf{I}$. to III., that the motions are truly dependent upon an internal voluntary influence of these animals. But as regards the supposition that they do not arise from any spontaneously contractile and expansible parenchyma, this is not proved. As the body of the Bacillarina, which is almost as transparent as water, is inclosed by a siliceous carapace, it is hardly possible, with our present optical resources and the ordinary methods of optical investigation, to observe the contraction of the body. Besides, the organs regarded by Ehrenberg as ovaries often exhibit such different arrangements, that we are easily led to imagine the existence of an expansibility and contractility of the parenchyma of the body.

2) "Ciliated organs occur in the vegetable kingdom in the form of ciliated epithelium in the spores of Vaucheria, and in the form of isolated, long whip-shaped threads in the spores and early stages of different Confervæ, among which we find several of the organisms described by Ehrenberg as Monadina and Volvocina." Siebold was evidently led to this assertion by a contribution of Thuret to the 'Annales des Sciences Naturelles,' which work

* Monthly Report of the Berlin Academy, 1841, p. 109. 
he quotes. Even if ciliated organs do really occur in the spores of Algæ, these cannot be regarded as true locomotive organs. Their peculiar motions, with which natural philosophers are at present so much occupied, also occur without locomotive organs, and take place in other substances, as small particles of dust. It appears to be proved by Ehrenberg's observations on the spores of Saprolechnia (Conferva ferax, Gruith; Achlya, N. ab Esenb.), which I can confirm, that chemical processes are the chief agents in it. This view finds support in the following discovery: I occupied myself for some time during the past summer with investigations on the process of germination in our Cerealia. The minute particles which occur in the cells of the grains among the large granules of starch, at first did not exhibit the least trace of motion; but as soon as germination began they moved actively, and when the first leaf sprouted out, the movements were so remarkable, that I could hardly distinguish them from those of the ripe spores of Achlya prolifera. Siebold's opinion, that in many of the organisms figured by Thuret we might recognise several which Ehrenberg has described as Monadina and Volvocina, is quite correct. But which of the two is in error? Is it Ehrenberg's fault, if Thuret figures Infusoria as spores of Algre? I shall hereafter enter upon Thuret's memoir in a separate communication and point out the errors contained in it.

3) "Many of these lower vegetable formations (Bacillarice and Diatomea) have been considered as animals from their locomotion, although the alterations in position observable in them do not give the slightest impression of their emanating from an internal will of the organism." It is at once obvious, that the actual impression which these minute creatures make upon the observer cannot afford grounds for deciding any question, for in matters of science we require objective grounds. I must also confess, that when $I$ first observed these animals, they gave me the impression of this alone. Hence we have both observed one and the same thing and derived different impressions from it.

\section{Covering of the Body.}

3. The Polygastric Infusoria are either furnished with a carapace or not. When present, it either consists of silica, which in many cases contains a considerable per.centage of oxide of iron, or it is more of a horny nature (Closterina). The carapaces assume various forms; being sometimes oval and truncated at the extremities, sometimes very narrow and pointed at the extremities, sometimes broad and symmetrically excavated at the sides, and many other varieties of form. Among those not having a carapace, there are some which are inclosed in great number in mucoid masses, as the Ophrydina, which live together frequently by hun- 
dreds in green globules not unlike frog's spawn. In the intestine of the frog we find forms, some of which (especially Bursaria ranarum) are inclosed in mucous envelopes, which reminds us of similar occurrences among the Entozoa.

\section{Locomotive Organs.}

4. They are present in various forms, and furnish us with a proof of the incorrectness of the view, that the lowest animal beings throughout exhibit a more simple, homogeneous, and consequently more imperfect organization than the higher ones. To survey them, we shall consider them in the three following: groups:-

1) Locomotive organs placed around the mouth.--The organs which belong here, in whatever form they occur, are apparently always organs of prebension, taste, \&c., and hence, strictly speaking, should be separated from the organs of motion. However, as they correspond to the hands and other like formations of the higher animals, they ought to be placed here. In the Rotatoria they are much more perfectly developed in the so-called rotatory organ, which appears in the most numerous and complicated forms. The Polygastrica exhibit more simple forms, but still sufficient difference to merit more accurate consideration. In their simplest state they appear as one or two filiform proboscides, frequently of such tenuity that they are only perceptible when seen in motion between minute coloured particles. They exist in greater number in Vorticella, Epistylis, Enchelys, \&c. In these instances they form a circle around the mouth, which consists of either one or two rows of cilia, and then frequently exhibit surprising resemblance to several kinds of rotatory organs. These ciliary circles exhibit differences according to the different form of the mouth. In many they are susceptible of retraction; this is most constantly the case in Epistylis grandis.

2) Locomotive organs which cover the whole body, or may be considered as lateral appendages.-In most of the Polygastrica these are likewise cilia, the usual arrangement of which is in longitudinal strix (probably muscular) corresponding to the axis of the body, to which the former are attached. They often appear in great numbers. In others the cilia are arranged in circles which surround the middle of the body cbliquely, as may be seen very distinctly in the Peridinaa. In Spirostomum ambiguum there is a row of cilia $(6 \mathrm{~A})$ running the whole length of the body. In the Stylonychia they are remarkably different. Their somewhat elongated oral fissure is surrounded by cilia of the usual structure, those on the body being more rigid. But what is most remarkable in them is, that they are not placed on the muscular striæ which run longitudinally down the body, but 
are more scattered, and are principally developed at the anterior and posterior extremities of the body. Each bristle (as these cilia are properly called) is articulated at the base, and is consequently susceptible of a distinct motion, whilst in the ordinary cilia their motions appear dependent upon the stria on which they are situated (fig. 2).

3) Locomotive organs belonging to the posterior part of the body. Several forms exhibit in this spot cilia which are not remarkable, but merely resemble those described under 2 ; others have small fibres, with which they fix themselves (Stentors); others again exhibit parts in which the muscular system in its primitive form may be more perfectly studied than elsewhere : I allude here especially to the Vorticellce. These animals are situated upon the extremities of simple or divided trunks, the structure of which, in those having the power of springing back, is as follows :-A sheath (muscular sheath), fig. $3 \mathrm{~s}$, incloses a simple muscle, which disappears a little above the part at which the sheath is attached to foreign bodies. The evident connexion between the motions of the body with those of the muscular peduncle shows us that the muscle ramifies within the animal itself. I have only succeeded in observing this ramification in Vorticella nebulifera. I saw two very distinct, although very small (not perceptible without a power of 400 diameters) fibres, fig. $3 v v$, stretching inside the body. Ehrenberg saw a similar extension of the muscle in the body of $V$. Convallaria. When this peduncle is not contracted, the whole body of the animal is in a state of full extension; but as soon as it contracts this, especially when it draws in the oral cilia, the sheath and the muscle both become shortened (the whole peduncle becoming spirally coiled) and the animalcule springs back on its peduncle; if the body becomes again extended, and especially if the oral cilia are very distinctly unfolded, the peduncle also passes from its contracted into the elongated state. The oral cilia and the whole of the anterior part of the body appear to be of importance in this retraction, since expansion and contraction of the trunk and body appear mutually conditional. What influence upon the motions we have just described must be attributed to the muscular sheath, and what to the muscle, has not yet been satisfactorily determined. This much however is certain, that for perfect retraction three conditions are requisite; - an uninjured state of the muscular sheath, an uninjured condition of the muscle, and attachment of the entire peduncle; for in Vorticella, in which the muscle was torn in the uninjured sheath, I observed, it is true, a contraction of the body, but it had no influence on the extension and contraction of the peduncle; in others, the sheath of which had disappeared, the 
muscle still remaining attached to the body, every attempt at complete retraction failed. In neither case had the animal become re-attached *. Among the Rotatoria we have an animal analogous to the retracting Vorticella in Conochilus volvox, in which however, independently of the fact that the separate animals in it do not grow upon foreign bodies, but are united together by their peduncle, the muscle which passes through the muscular sheath divides into three or more bundles, which run separately in the body of the animal and are firmly attached to its internal surface.

The Vibrions indisputably exhibit the most active movements, but with our present optical resources it is impossible to discover either organs of motion or any muscular structure in them.

\section{Alimentary Canal.}

5. Most of Siebold's objections to Ehrenberg's views have been made against this part of the subject. In the following remarks I shall consider the individual parts of the alimentary canal in order, and test Siebold's opinions at the proper places.

1) Mouth.--A mouth has not been directly recognised in all Polygastric Infusoria; still in several of these dubious cases we may with certainty conclude as to its presence, either from alimentary matter being taken internally, or from one to two long cilia which we usually find around a mouth, or from some other circumstance. When distinctly present it forms sometimes a more or less roundish aperture (Paramecium, Enchelys, \&c.), sometimes a longish fissure (Stylonychia), sometimes a spiral (Spirostomum), sometimes an aperture of some other form.

Dental structures, in comparison with those of the Rotatoria, in which they occur in such a variety of forms that a treatise might be written upon them alone, are very rare, and can scarcely be observed in any others than in Chilodon, Nassula and Prorodon teres. In these animals the circular oral aperture is internally covered with a ring of longish bristly teeth. According to Ehrenberg, these are forced out of the oral aperture in P. teres by drying the animal $\dagger$. I have observed this Infusorium once only, and as I was not prepared for this phænomenon I overlooked it; but I distinctly saw in it the glands (six), which were not then known to him. The peculiar structure of the mouth

* As far as I know, the influence of the muscle and muscular sheath upon these motions has not been considered. It is therefore to be hoped that when favourable conditions present themselves, such as the injury of one of these parts, they may be taken advantage of in order to ascertain with certainty what share is taken by the muscular sheath and what by the muscle in the rapid contraction.

+ Schriften der Berliner Akademie, 1833, p. 308, and Infusorien, p. 316. 
in Paramecium siomioptycha* is worth notice. It is surrounded by three to four annular tibres $a$, which are of a tougher and more solid structure than the rest of the body; in it occurs a peculiar appendage $z$ (rudiment of a tongue?).

We must now minutely examine another remark of Siebold. This philosopher divides the Protozoa (by which term he designates Ehrenberg's Polygastrica) into Astoma and Stomatoda, referring to the former the Astasice, Peridinaa and Opalina, and to the latter the remaining families of the Polygastrica. Independently of the question whether this division is natural, some parts must be corrected. As regards the Astasice, the mouth has certainly not been distinctly recognised, but may be imagined to exist in several. All the Peridinac cannot possibly be referred to the Astoma, because $P$. pulvisculus $\dagger$ and cinctum $\ddagger$ are by no means destitute of mouth. Among the Opalina, Siebold has evidently taken $O p$. ranarum, Val., Bursaria ranarum, Ehrenb., as his type, as is shown elsewhere. Whether the author refers the remaining components of the genus Bursaria to the family of the Opalina or not, in no case can they be referred to the Astoma; for I have seen a distinct mouth in Bursaria truncatella, flava, and when young, ranarum. That the latter has not hitherto been found to take up particles of colouring matter or other nutriment internally does not appear very strange to me; for these animals live inside others, the fluids of which are so delicate that solid substances are not fit for their nutrition. Even if the oral fissure could not be pointed out, I should still hesitate to place so much value upon this distinction; for in taking such nutritive substances as the Opalina feed upon, a simple mere oral spot, a part of the body of more delicate structure than the other parts, especially adapted to the passage of animal juices as nutriment, would be sufficient. We have similar instances in the intestinal worms. Their proboscis has no mouth, still pouch-like organs proceed from the anterior part of it which cannot well be considered as anything else than alimentary canals.

2) Intestinal Canal.-The nutritive matters which have been taken by the mouth next arrive at a cavity which runs through the body in a direction varying in different genera (fig. $5 s$ ). The gastric cells $z$ are appended to this by means of hollow peduncles $i$. We might be easily led to consider the cavity $m-a$ as an intestine ; its function however does not admit of this supposition, as it merely serves for the transmission of the nutriment,

* Ehrenberg found this new species in the summer of 1845 on Ectosperma clavata, and had the kindness to give me some specimens of it for examination. (See contractile vesicle.)

$\uparrow$ Ekrenberg, tab. 22. fig. 11.

$\ddagger I b$. tab. 22. fig. 22. 
which accumulates in the individual cells only, and is here applied to nutrition. Its physiological use therefore is merely as an cesophagus, the separate cells performing the functions of stomach and intestine. The substances return from the gastric cells into the common cavity, travelling from one cell to the other, and are finally evacuated by the anus. These intestinal phænomena cannot all be directly observed, so perfectly as we have just traced them, at one time and in a single individual, because they are of a delicate transparent structure and of the same refractive power as the parenchyma of the body; separate observations however compel us to adopt this view.

$a$. In such forms as are not too minute, we can distinctly observe how the nutriment or articles of food artificially supplied, constantly take a definite course in the body; in some instances the first portion of the alimentary canal can be observed when not in action, as in Epistylis grandis; it is then frequently seen to be covered on the inner surface with cilia, and which in the Opercularia may even be counted.

$b$. But that the alimentary canal, the commencement of which, as just stated, is distinctly perceptible, does not extend through a limited extent only of the body and then terminate, can also be proved in Epistylis grandis. If this animalcule takes colouring matters, we perceive that when these have passed through the course of the intestine, which can also be seen when the animal does not eat, a large piece frequently pursues its course for some distance and then only enters a cell.

$c$. In the same animal I once attentively observed what appeared to be the extremity of the intestinal canal, fig. $6 r$, to ascertain what the further course of the coloured particles would be. At this time the animal had not filled any of the cells in its inside; suddenly both $i$ i were so, although I had not perceived any nutriment pass by $r$. This clearly points out that the two cells must be in connexion with the common cavity from which they had become filled; and when, after the animal has fed for a considerable time, we see that similar filled cells are diffused throughout the body, this phænomenon affords a ground for the supposition that the intestinal cavity is of greater length than we should at first sight imagine.

3) Anus.-In by far the greater number of cases the absorbed substances are ejected by a distinct aperture. In a great many it has been directly observed, and in these is sometimes placed at that extremity opposite to the mouth, at others near to or at the side of it; whilst in others we can often conclude as to its presence by a distinctly defined spot.

I believe that the above observations are sufficient to prove the correctness of the view I have taken of the intestinal canal of 
the Polygastric Infusoria. In what follows, some other phænomena will give support to it, and as I hope will remove any doubt still remaining.

We shall now revert to the consideration of Siebold's view of the means of nutrition in the Polygastrica. As he has separated the Astoma and Stomatoda, he is obliged to search for a method of explaining their nutrition. He has selected that which is most ready in such cases, viz. nutrition through the common integument of the body. In those forms in which a mouth or gastric cells filled with colouring matter have not been directly observed (such are extremely few, for the latter has been observed even in the Navicula, Closterina and Monadina), we will willingly adopt this obscure method of nutrition until further and more certain observations have been made. But as regards the genus Opalina, which Siebold has especially selected as his type in separating the organs of nutrition of the Astoma, we will examine his opinion on this point. He says (p. 15) :-

"The Opaline do not exhibit an oral aperture upon any part of the surface of the body, never take particles of colouring matter into their interior, nor can foreign solid substances, perhaps swallowed as nutriment, ever be detected within them. But that these Opalina are capable of absorbing fluids by means of the surfaces of their body, we recognise in such individuals of $O p a-$ lina ranarum as have existed in a rectum containing a large quantity of bile; they have then become coloured greenish throughout. If the Opaline, which require a certain amount only of moisture for their existence, are placed in contact with water, they absorb too much of this fluid, becoming greatly distended and gradually dying. In these Opalince the absorbed moisture accumulates in densely aggregated transparent vesicular drops beneath the cutaneous integument; cavities like these filled with a transparent fluid in the Infusoria have been designated by Ehrenberg as gastric vesicles (ventriculi), and by Dujardin as vacuoles." I have already slightly alluded to this remark in considering the mouth, and shall merely add the following. The vesicular drops here spoken of by Siebold do not arise from the absorption of water, for they are also seen in those specimens which have been removed from the frog's intestine without the addition of water. They are certainly more visible in the latter, because the animals, which are somewhat folded up in the intestine, are then capable of expanding themselves. Moreover, it is incomprehensible how, in those individuals which have lived in an intestine filled with bile, this is diffused throughout the body, but not also in such vesicles as the water occurs in, or at least why the water which appears in vesicular drops should not be coloured by bile in these cases. The conditions of the nutrition of the Stomatoda, as detailed 
above, have also been disputed by Siebold. His views of them, according to $\S 12$, are essentially these:-The Polygastrica swallow nutritive matter (coloured particles) with the water. So long as this remains at the lower extremity of the osophagus*, it appears as a pedunculated vesicle. It is loosened by the contraction of the osophagus and then appears without a peduncle, and containing the bodies which have been swallowed, perfectly inclosed within it. The swallowed masses in the form of vesicles mutually press upon one another in the body when the animals have eaten too much, the earlier yielding before the subsequent ones. It sometimes happens that these drops when filled with solid food run into one another, which shows that they are not surrounded by a distinct (gastric) membrane. Against this ingenious supposition we have the following objections:-

$a$. No oesophagus has been proved to exist by observation, which continues for a certain distance within the body and then stops; the above phænomena rather indicate that an uninterrupted canal runs through the body from the mouth to the anus.

$b$. Hence the entire theory of the vesicles is untenable; this is confirmed by various observations and considerations.

In Vorticella microstomat I often perceived how the nutritious matter about to be swallowed was formed into a minute ball in the anterior part of the oral aperture-I cannot better designate it than as a morsel. After this was effected, it was swallowed by the animal in such a manner that the separate particles remained united, as they had become in the oral aperture. The morsel then passed through the intestine for a considerable distance in the body, and appeared of the same form in a gastric cell. Certainly no drop inclosing the nutritive matter had formed at the lower extremity of the supposed oesophagus, for the formation of the morsel occurred in the oral aperture; but to admit that the morsel had become inclosed in a vesicle of water at the end of the œsophagus, or any such attempts at explaining this fact, would be opposed to physical laws. In other instances, and this may be observed with distinctness, especially in Epistylis grandis, when colouring matters are present in great quantity, the entire cavity is sometimes filled as far as a cell. On examining a mass of colouring matter, as $z$, fig. 6 , without a drop of water in which it might be inclosed, and the continued filling of this cavity with solid particles, every appearance of the vesicle, as described by Siebold, vanishes. I have observed the running: together of these aqueous vesicles inclosing solid matters but

* Siebold denies the existence of an alinentary canal, and supposes the presence of an osophagus which only enters the body to a limited extent, and then terminates.

+ Ehrenberg, tab. 25. fig. 3 . 
very rarely, and only when the animals were dying. Even if Siebold has seen it frequently and always in living specimens, which I however doubt, still he cannot conclude from this, that these spaces are not inclosed by any membranes; might they not be rent by the mutual pressure of the filled gastric cells on account of their delicate structure?

I shall conclude the considerations of the alimentary canal with an observation which appears to me especially adapted for disproving Siebold's views; it is this: Ehrenberg discovered that when carmine and indigo are nixed with water containing Paramecium Aurelia, in a short time some of the cells of the animalcule are occasionally filled with the red colouring matter only, others with blue. I have also seen this; it was first shown me by my teacher himself, and I have several times subsequently observed it. Siebold's mechanical explanation, in my opinion, is not sufficient to account for it; it constitutes a phænomenon which presupposes a tolerable development of the sense of taste.

Remark 1.-At p. 16 in note 1, Siebold says: "That organ which occurs in Trachelius Ovum and is regarded by Ehrenberg as a branched intestinal canal, has always appeared to me to be a fibrous, certainly not hollow cord, which runs through the extremely loose parenchyma, giving the interior of the animal a coarsely reticulated aspect by its ramifications." I have hitherto seen this animalcule twice only, as it is rare, and I cannot therefore form any definite opinion upon this organ. But I may assert with certainty that Siebold has either never seen it in a natural state, or has entirely mistaken its structure ; for it requires a mere glance through the microscope to be convinced, that the question of its being a fibrous organ cannot be entertained for a moment.

Remark 2.- If Siebold denies the existence of an intestine in the Polygastric Infusoria, I am not aware how he can correctly denominate the excretory spot the anus, and why the excrements cannot exude from every part of the body.

\section{Propagation.}

6. The organs by which the preservation of the species is effected have always had a peculiar interest with physiologists, and have hence been treated of with a particular satisfaction. The delicacy of the parts and the mystery of the sexual process have a special charm with investigators, which is still more increased in the Infusoria by the minuteness of their forms. I shall therefore enter fully upon this point. If we first ask ourselves-how the Polygastrica are propagated?-it must be answered :

1) Viviparously.-Ehrenberg first observed this in Monas vivipara, in which the phænomenon is common. Moreover a some- 
what similar occurrence is seen in Stentor caruleus, to which I shall recur presently. Siebold appears to have overlooked this ; for at p. 23, as the means of propagation of the Polygastrica, he only enumerates division and the formation of buds.

2) By Zygosis.--This has hitherto been observed in the animal kingdom only in the Closterina. In autumn we find young Closteria of such a form, that two globules, each of which is elongated on both sides into a point, have become adherent. Unfortunately their further stages of development have not yet been seen. We do not know whether perfect Closteria are formed by an intimate growing together of the globules with their elongations or by a progressive separation, although the former is probable. Should we be so fortunate as to clear up this point, and should the zygose prove to be a mode of propagation of the Polygastrica, it would not be so rare hereafter; ffor it has also been observed in species of Spirogyra and a mould-formation.

3) By division.-This occurs either transversely or longitudinally, or in one and the same species in both directions. It is evidently, in many families, one of the most productive methods of propagation, as in the Bacillaria, Kolpodea, Stylonychice, \&c. In the former the siliceous carapace divides regularly, and this might perhaps form another ground for enumerating them among animals.

4) By formation of buds.

5) Formation of ova has certainly not been directly observed, but the different sizes in which many Polygastrica, especially Vorticella, occur, perhaps allow us to conclude in favour of its existence. The difference in the size of Vorticella microstoma is most remarkable. In no instance could the individuals of this species, which are all so very small, be produced by division; nor by the formation of buds, for such has not yet been observed in them. I shall here mention an observation which I made in the early part of 1845 upon Stentor caruleus to connect the further reflections on this point.

Plate X. fig. 7 exhibits this Infusorium. Within it I observed three or four globules in different states of development, which are represented in a row in figs. 8-14. In the first stage the contents of the globules, consisting of minute granules, exist most imperfectly developed; but few granules at present occur, and the globule, when it lies in the body, is not very distinct on account of the granular parenchyma of the latter. In the second stage of development, fig. 9 , the granules appear more numerous, the contents are therefore more concentrated, and the globules can then be very distinctly observed in the body. Fig. $10 a$ shows the third stage; granules commence arranging themselves in a row $m$. They sometimes appear grouped in the same man- 
ner at two spots, as shown in fig. $10 \mathrm{~b}$. The granules thus arranged and closely pressed together blend into a glandular but clear organ, in which the granular structure cannot be any longer detected; frequently it is also divided into two parts, figs. 11 and 12. Lastly, in the situation of the transparent glandular organ a row of cilia appears, evidently the mouth (fig. $13 a$ ); but whether the latter is formed immediately from the former I have not been able to ascertain with certainty, but it is extremely probable, since on the one hand the row of cilia occurs in the situation of the bright gland, whilst, on the other hand, in all the germs which exhibit this the former organ is absent. Simultaneously with the development of the mouth there appear one or two clear vesicles (figs. 13, 14b). On the 18th of May I observed in the interior of St. caruleus a germ as in fig. 13; I saw the cilia very distinctly in motion; the vesicles were however still absent, and they did not escape on this occasion. On the 21 st I saw the perfect form, fig. 13, which issued out, whilst the parent animal swam away. I now attentively observed the young one to follow up its further changes, perhaps the bursting of the carapace; but I was obliged to leave off watching it in half an hour, as I could not vouch for the accuracy of further observation on account of the strain upon my eyes. On the 4 th of June I saw a germ escape, as in fig. 14; it differed from that observed on the 21st of May, for, being at first round, it at once exhibited an incurvation at its lower extremity, an appearance frequently observed in young Stentors, sometimes in old ones, when they contract from the elongated form to one more or less rounded. I have subsequently once seen the escape of a similar germ, and it appears to me that the true point of maturity is that at which vesicles begin to be visible. In Stentor polymorphus, fig. 15, I have observed two such globules, but I have not succeeded in seeing any perfectly formed escape. In autumn I have often sought for the recurrence of this phænomenon, but have never been able to observe it so perfectly as in the spring, although similar globules are not rare in the later parts of the year.

How can we explain this phænomenon? It can hardly arise from Vorticella which have been swallowed, as has been proposed to me in conversation, since I observed such various conditions of development, which were moreover never observed except in one part of the body, never more anteriorly, which is hardly possible if they were substances which had been swallowed. I rather think it formed the earliest commencement of the formation of buds, which usually appears at this part of the body. But it is also possible that it is a pcculiar kind of propagation, which Steenstrup* and others have observed in many intestinal

* On the Alternations of Generation. 
worms, and which consists in this, that in the interior of the parent animals, germs (which had not hitherto been shown to be a consequence of sexual influences) are formed and separated. The fact which I have stated, that I have seen these globules escape, appears to support this view.

We have as yet been purposely silent on the true organs of generation, so as to be able now to devote ourselves to their consideration alone. Ehrenberg has mentioned as sexual organs one or two contractile vesicles and glands occurring either singly or in considerable number*. I shall consider both minutely, and see what signification they admit of.

A. The contractile vesicle.-If we exanine a Stylonychia (Pl. IX. fig. 2) or a Bursaria, we observe, with a little effort, a bright, tolerably large vesicle. At first sight it appears to be a round aperture in the skin, whence it has happened that many observers have considered it as having some relation to the respiration; this however is by no means the case, for it lies within the body. We may easily convince ourselves of this fact by observing the animals (as Ehrenberg first stated) whilst revolving on their longitudinal axis. At those moments when the vesicle disappears, we see distinctly how the lines which cover the whole body longitudinally and are covered with cilia are drawn over the spot which is apparently open. It is often difficult to discover the vesicle on account of the number of granules which exist in the skin. The most common and very constant form is the globular; we scarcely ever notice any form which differs materially from this. But in some genera radii occur which traverse the body in a stellate manner, and are sometimes longer, at others shorter (fig. 4). The varieties in the number of the vesicles are likewise slight; there are usually one (in most genera) or two (Paramecium, Chilodon Cucullulus). Sometimes indeed several occur, but then usually the animal is in the act of division. In $\S 17$ of Siebold's work there is something to correct. According to his account, Trachelius Meleagris is covered with a row of from eight to twelve round contractile cavities (p. 21); and Ehrenberg regards the colourless juice they contain, in consequence of an optical illusion, as gastric cells filled with a reddish gastric juice. But the fact is this : the eight to twelve round vesicles do not appear red as the result of an optical illusion, but in consequence of the coloured juice contained in them; for when the animals dissolve, the red juice is seen to pour out. This animal also exhibits two other vesicles, which are the true contractile bladders. Those occurring also in Amphileptus Meleagris and longicollis appear to me to correspond to the eight to ten vesicles in Trachelius. Meleagris, as

* On a donble condition of the sexes demonstrable as far down as the Monadina. 
their contractions did not appear to me to be the same as I had been accustomed to see in other forms. Siebold ascribes to Spirostomum ambiguum a contractile reservoir in the form of a long pulsating vessel which runs through the longitudinally-extended abdomen. I have never seen this; perhaps Siebold has mistaken the two to four rows of cilia, which we have mentioned, for it. In Stentor also, in addition to the large round contractile spaces at the anterior extremity of the abdomen, there are several such spaces extending down the abdomen laterally. In my own examinations on the generative relations of the Stentors which I have already detailed, I have examined several hundred specimens, but, except the large contractile cavity, have never seen anotber situated laterally on the abdomen. Probably Siebold has examined the first stage of development (perhaps as fig. 8). The most important physiological property of this vesicle, as already pointed out, is its contractility. We see how, from time to time, it contracts powerfully, frequently spasmodically, again expands and repeats the contraction. In those cases in which the vesicle exhibits stellate extensions, these are expanded at the base so as to resemble a bulb, just as if some fluid contents had been impelled into them, which however has not been shown to be the case. The contractions in some occur regularly, in others irregularly. With a view to this point I observed, with Schmidt, Paramecium Aurelia, Stylonychia pustulata and Bursaria flava. We found that in $P$. Aurelia, from the commencement of one contraction to that of the following, six to eight, and in Stylonychia about ten to twelve seconds elapsed, but that in Bursaria the interval between the recurrence of the contractions was so short that it could not be estimated. Let us test by these observations the general correctness of Siebold's conclusion, "that there are hollow, rhythmically contractile, as it were, pulsating cavities in various forms, numbers and arrangement."

As regards the occurrence of contractile vesicles in the separate families, it has been proved in most of them. Even in the first treatise on this subject* attention was drawn to their presence in the greater number of forms, and instances have since been made known, in Ehrenberg's separate treatises, in which they were shown to exist, although formerly they appeared to be wanting. However, they have not been recognised hitherto in the following families (probably on account of the inadequacy of our optical means or other circumstances): Vibrionea, Arcellina, Bacillarina, Closterina, Colepina and Dinobryina.

B. The glands.-In addition to the vesicles, we find in almost all Polygastrica, glands of a somewhat more solid structure than

- Ehrenberg, l. ult. cit.

Ann. \& Mag. N. Hist. Vol. xviii, Suppl. $2 \mathrm{~K}$ 
the rest of the body. They are best seen by allowing the Infusorium to decay from the deficiency of water without removing: it from the glass-slide. In the work above quoted, Ehrenberg distinguished the following forms, among which all the varieties may be comprised :-

1. The globular; 2 . the ovate; 3 . the discoid; 4 . the reniform; 5. the ligulate; 6 . the moniliform; 7 . the cylindrical; and 8 . the annular. They appear to be more general than the vesicles, but have not been found in some, although few families. These are the Colepina, Vibrionea, Dinobryina and Arcellina. In regard to these organs also I find in Siebold $(\$ 21-23)$ some remarks to which I cannot assent.

$a$. The nucleus appears to him to be loose in the parenchyma, as the observation can be frequently made that the Infusoria revolved around the nucleus which remained at rest in their interior. This appearance however cannot so often be perceived, and only when we attentively observe the glands for a considerable time; it never appears when we first commence observation and observe both the glands and the body. I therefore consider this phænomenon as an optical illusion, especially when I recollect that it would be inexplicable how the glands in the different genera and species preserve so constant a position, which could not be expected in so yielding a parenchyma of the body as Siebold has presupposed in his consideration of the relations of nutrition to exist.

b. At p. 25, in note 2, Siebold supposes that the glands perhaps subsequently became developed into distinct animals, because after the death of the Infusoria they were not immediately destroyed. This also appears improbable to me, because I frequently saw these nuclei disappear even in half an hour or an hour, although water was present in sufficient quantity. That they are preserved longer than the rest of the body ought not to occasion surprise, as they are of a more solid consistence.

Remark.-As regards the occurrence of glands and vesicles in one and the same individual, it must be remarked that in all cases where a vesicle is present the gland has also been shown to occur, or certainly may be demonstrated to occur, as several observations have shown us (Prorodon teres), but that there are some families in which the glands, but not the contractile vesicles, have been seen (Bacillarina, Closterina). If both organs are present at the same time, and we coincide in Ehrenberg's view on the use of these organs, the supposition becomes probable that they are connected with one another. This however has by no means been confirmed.

C. Import of these two organs.

Ehrenberg considers the glands as testicles and the vesicles as seminal vesicles. In truth, this view has not been expressed by 
him without reason. The analogy of this vesicle with the con. tractile organ of the Rotifera, which appears from its evident connexion with the ovary to be the seminal vesicle, is in favour of this view. Wiegmann, in mentioning Ehrenberg's discovery in his annual report*, remarked, that perhaps the contractile vesicle might be a heart. He states, as his ground for this supposition, that it is always formed before the longitudinal and transverse division of the body of the animal, which might appear to indicate that it was connected with some organ essentially necessary to the vital process ; whilst, on the other hand, the organs of propagation, which under other circumstances did not commence their functions until the body was perfectly formed, do not require so early a formation nor so constant an action. However, it appears to me that Wiegmann's objection is weakened on the one hand by the consideration that the division is always an essentially distinct formation of the individual from that of sexual reproduction, and hence that the laws of the development of the two modes of formation of new individuals are by no means identical ; on the other hand, by the supposition that at every contraction seminal fluid is not evacuated. Siebold with Wiegmann also considers the contractile vesicle as the first form of a circulatory system and the first attempt at a circulation of the nutritive fluid, but merely as a consequence of the following presupposition: "Most probably the liquid filling the cavities which become distended by a kind of diastole is a nutritious fluid emanating from the parenchyma, which at the systole is again propelled into the parenchyma, whence the necessary motion and distribution of this nutritive fluid are effected and its stagnation prevented." As Siebold's view is based upon this alone, and believing that I have removed Wiegmann's objections, and Ehrenberg's view having at least one analogy, although of itself not sufficient, I prefer the opinion of the latter; but I must not conceal the fact, that the occurrence of glands without vesicles (in the Closterina and Bacillarina) appears to show that the connexion of these two organs is not essential. Still it is not impossible, that by the perfection of our optical resources the contractile vesicle may be detected in these families also.

Remark.-It would have been an important point to have also taken the eyes (of both the Rotatoria and the Polygastrica) into consideration; however, as Schmidt in his paper on the Rotatoria has likewise omitted this, it affords matter sufficient for a distinct treatise.

- Wiegmann's Archiv, 1831. 


\section{EXPLANATION OF PLATES IX. AND X. \\ Plate IX. B.}

Fig. 1. Closterium acerosum: oo, vesicles containing granules in constant motion; $s^{\prime \prime} s^{\prime \prime \prime}$, minute thin cords, which $I$ saw change in relative position; $d d$, glands ; $m$, aperture (mouth) ; $r r$, apertures which occur in some other species of Closteria, and from which Ehrenberg saw minute feet project.

Fig. 2. Stylonyehia pustulata: $m$, mouth; $b$, contractile bladder ; $f$, rigid bristles, moveable upon their bases.

Fig. 3. Vorticella nebulifera $: b$, contractile vesicle; $z$, gastric cells; $s$, muscular sheath ; $m$, muscle ; $v v$, elongations of the muscle ; $f$, attachment in the muscular sheath.

Fig. 4. Paramecium stomioptycha: a a a, fibres which form a circle around the oral aperture $z$, its minute appendix; $d$, gland; 8 , contractile vesicle with its appendages.

Fig. 5. A Vorticella: $m$, mouth; $s$, general alimentary canal (œsophagus); $z$, gastric cells; $i i$, their hollow peduncles; $a$, anus.

Fig. 6. Episiylis grandis : $m$, mouth; $i$, gastric cells, which I saw filled, without having seen the nutritious matter pass the apparent extremity $r$ of the cesophagus; $z$, flled gastric cells in connexion with the general alimentary canal.

\section{Plate X.}

Fig. 7. Stentor caruleus : $b$, vesicle; $k$, germ; $d$, gland.

Figs. 8-14. Stages of the development of the globular body observed in its interior.

Fig. 15. Stentor polymorphus: $b$, contractile vesicle; $d$, gland; $e$, germ, as described under St. caruleus.

XLVII.-Descriptions of three newly-discovered British species of Coleoptera. By T. Vernon Wollaston, B.A., F.C.P.S.

[With a Plate.]

Section NECROPHAGA.

Fam. Mycetophagide, Westwood.

Genus Atomaria, Kirby.

1. Atomaria pallida. Oblonga, pubescens, corpore toto, oculis nigris antennisque testaceis exceptis, pallido-testaceo. Pl. IX. fig. 1 .

Corp. long. lin. $\frac{3}{4}$. Depressed, thickly punctured, slightly shining and pubescent. The entire insect of a uniform pale testaceous hue, with the exception of the antennæ, which are slightly darker, and the eyes which are black. Thorax broad; antennæ long and robust, the three apical joints large, forming a club, the terminal one slightly paler than the rest.

Taken at Fulbourn near Cambridge. Three specimens are in my own cabinet, and one or two more in the possession of the Rev. Hamlet Clark of Northampton. 
Ann.\& Mag. Nat.Hist. Vol.18. Pl.1X.
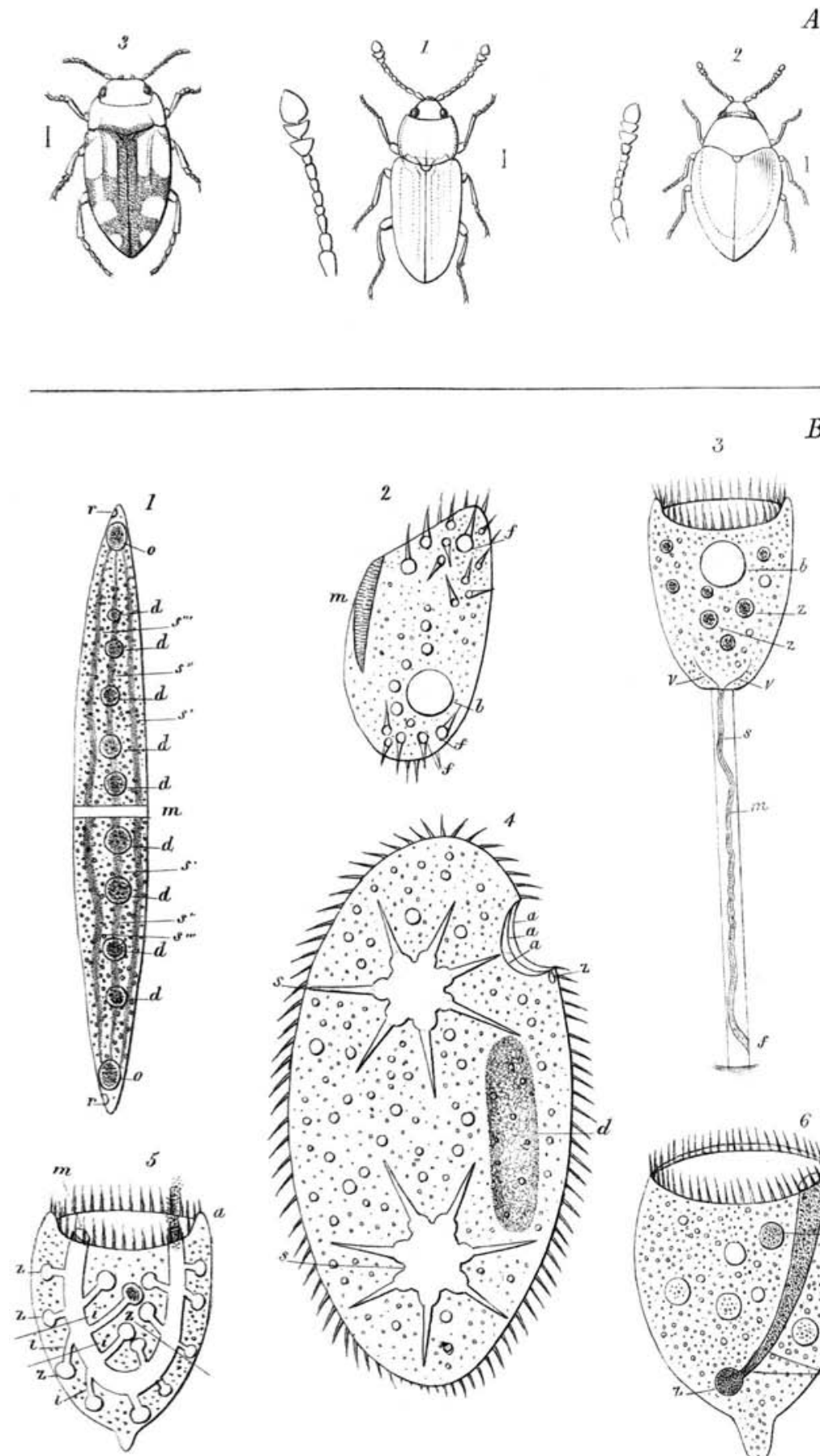

3
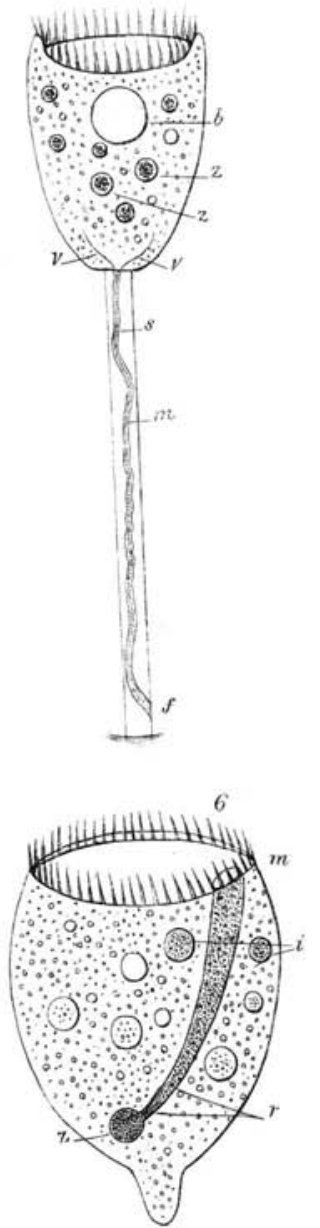

J. De.C.Sownterse? 
Ann.\& Mag. Nat.Hist .Vol.18. Pl.X.

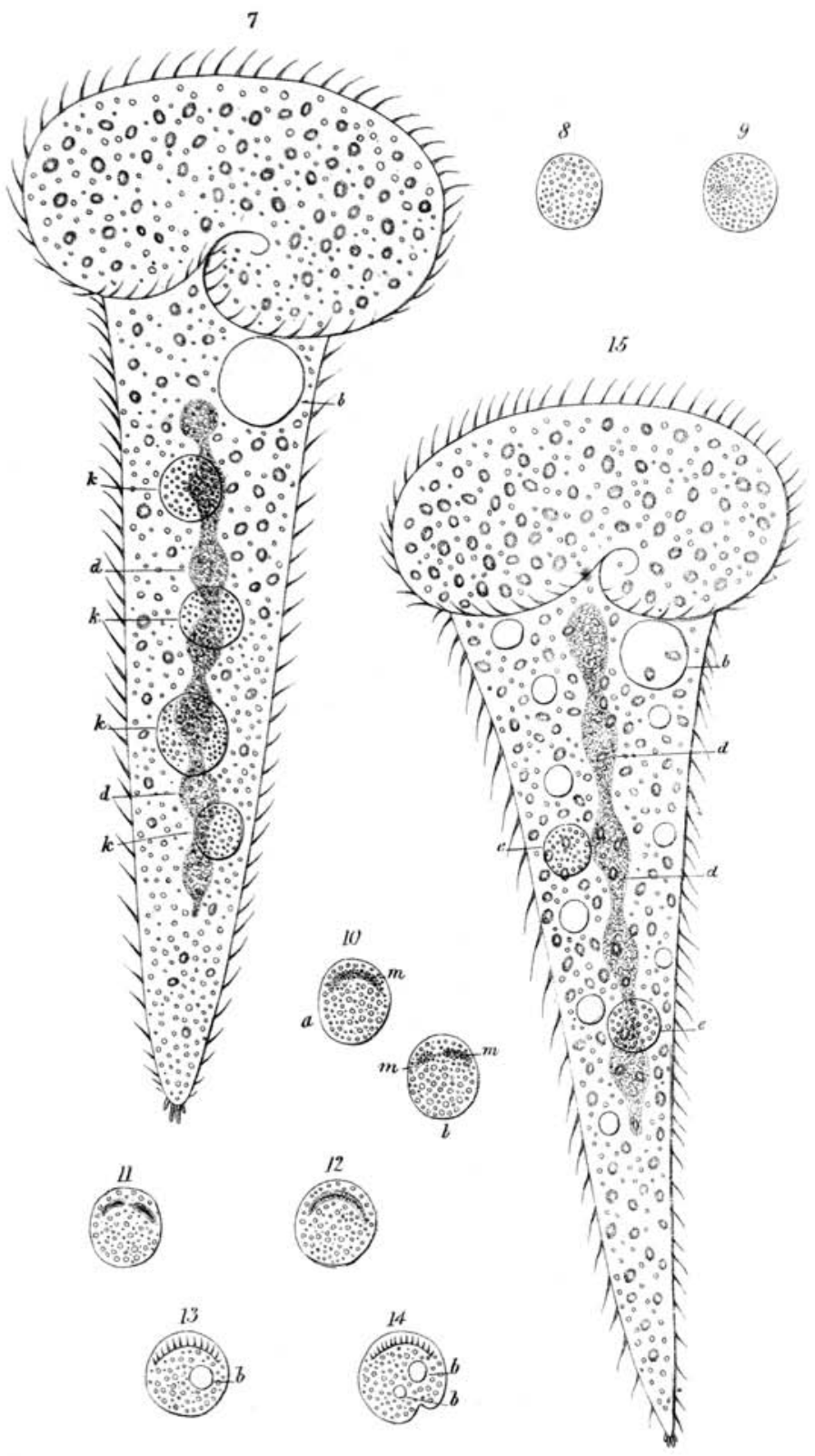

